\title{
Environmental and social impacts of electricity utilization: broadening the debate
}

\author{
G. Hugh Sidaway
}

Published online: 23 January 2008

(C) The Author(s) 2008

\begin{abstract}
Exposure of small laboratory animals to powerfrequency high-voltage electric fields was reported to have endocrinological effects, including changes in pineal melatonin levels. It has been assumed that these results are directly attributable to electric-field effects, but this article suggests that air ionization, produced by corona activity at the animals' body surfaces, may have been biologically active and could be relevant to the interpretation of some epidemiological and other studies. Although presently a matter of dispute, there is evidence that atmospheric ionization may be biologically active and could provide an alternative explanation for at least some apparent electromagnetic field interactions with biological subjects. Consideration of the electricity utilization environment as a whole, rather than one selected component, could allow the introduction of lower-cost, precautionary and putative hazard remediation measures.
\end{abstract}

Keywords Air ions - Corona discharge - Electro-culture . ELF-EMFs - Melatonin · Powerline health hazards · Remediation

\section{Introduction}

This article is an attempt to expand the scope of research considerations relating principally to possible health hazards associated with the electricity utilization environment. Much previous research in this area has concentrated on direct effects of the electric and magnetic fields of electricity transmission, distribution, supply and utilization

G. H. Sidaway $(\square)$

111 Waun Fach, Pentwyn, Cardiff CF23 7BD, UK

e-mail: derlwyn-research@ntlworld.com equipment. Although some very high-voltage transmission is effected by direct current, most of the global electricity utilization network operates by alternating current, generally 50 or $60 \mathrm{~Hz}$, but with some lower-frequency (16.67 or $25 \mathrm{~Hz}$ ) transportation systems.

The utilization network is often regarded as a generator of low frequency, non-ionizing electromagnetic radiation, collectively designated ELF-EMFs or EMFs for short. The definition of 'non-ionizing', however, has diverted attention from the ability of many electrically energized structures to generate air ions by transient corona discharge action even at low voltages: for example, the sparking of electromechanical relays used in older telephone exchanges operating at less than $100 \mathrm{~V}$ (Smith 1978). The 'indirect' hypothesis of corona ion bioactivity (Henshaw et al. 1996; Fews et al. 1999a, b) is discussed by, e.g., NRPB (2004). But more general recognition of possible direct biological activity by this category of airborne agents is overdue in the context of the 'electricity and health' debate and could allow the introduction of some novel remediation measures developing from the precautionary principle.

Present concerns over possible health hazards of EMFs derive from publication, starting from 1979, of epidemiological studies demonstrating an association between cancer and residential proximity to electric power overhead distribution and supply lines (Wertheimer and Leeper 1979, 1982; Savitz et al. 1988). These reports coincided with increased accessibility (e.g., Free et al. 1981) of some results of high-voltage electric-field experiments with small laboratory animals.

The experimental results which attracted the most widespread attention were those relating to the depression of nocturnal pineal melatonin levels in rats exposed to highvoltage alternating electric fields as reported by Wilson et al. (1981 and 1983), but using equipment described in detail 
by Kaune (1978a). In a subsequent article, Stevens (1987) postulated that domestic or occupational electric power EMFs could mimic the action of light-at-night, modulating hormone levels. A widespread belief has developed from these publications that power supply EMFs may reduce pineal melatonin. This view however is based on a narrow interpretation of laboratory experiments which actually demonstrated that exposure to certain 1.7 to $65 \mathrm{kV} / \mathrm{m} 60-\mathrm{Hz}$ electric-field environments influenced pineal melatonin. As noted by Lee et al. (1995), there have been difficulties in reproducing the original electric-field results, and it will be suggested here that air ionization, produced at the animals' body surfaces, may have been biologically relevant. Later work concentrated on power frequency magnetic fields, but these will be considered only briefly in the present article.

Attention should be drawn however to the observation of Barnothy (1964, p. 21) that apparent biological responses to magnetic fields may actually reflect a magnetic influence on some other agents such as irradiation. Thus in the case of ambient gamma irradiation, the paths of secondary electrons may be altered sufficiently to change the total number of ions produced per unit volume, resulting in potentially biologically significant, but presently unquantified differences between the atmospheric electrical environments within activated and unactivated laboratory Helmholtz coils.

\section{Research methodology}

To identify the bases on which presently operational hypotheses have been erected, it is necessary to examine some early research publications. Conversely, some effectively unpublished research has impacted negatively on a fuller understanding of this complex field. Thus the extensive, but largely unpublished, work of the UK Electro-Culture Committee is now almost unknown to the general scientific community (and is not cited for example by Soja et al. 2003) but must be relevant to a comprehensive study of overhead powerline bioeffects.

For the present article a range of published materials have been accessed, including some older references, together with unpublished information which should be more readily available. Access details for the Electro-Culture Committee Reports and Minutes are presented in the Appendix.

\section{Results and discussion}

\section{1 $60-\mathrm{Hz}$ electric-field laboratory studies}

Comprehensive studies in the 1970s were sponsored by the U.S. Department of Energy to examine possible effects on living systems of electric fields associated with projected high-voltage electricity transmission. The experiments were designed to "eliminate or minimize" the influence of secondary factors accompanying high-voltage electric-field generation. Thus precautions were taken to avoid corona discharge from electrode surfaces, but the possibility of corona activity at the animals' body surfaces was not considered, and the involvement of air ionization cannot therefore be excluded, as has been widely assumed.

Experimental details were provided by Kaune (1978a). In some experiments, animals were divided into three treatment groups: "exposed" and "sham-exposed", both of which were housed within a single laboratory room, and "cage control" in a different room. The first two groups were separated by "...walls consisting of two grounded layers of $2.4 \mathrm{~cm}$ mesh poultry fencing...." (Free et al. 1981, p. 107). These would not have prevented horizontal circulation of some airborne material between the various compartments, but could have preferentially intercepted some more mobile, electrical charges. No details of laboratory ventilation were given.

It is not clear if "cage controls" were included in all experiments but results for this group, reported in Tables X1 and X2 of Free (1978), showed statistically significant reductions in body weight, thyroid weight and some hormone levels in both exposed and sham-exposed animals within the treatment room, when compared with unexposed animals in a different room.

This important point has not been given adequate attention by various reviewers but is consistent with an interpretation based on airborne bioactivity: animals housed within the treatment room, even those untreated by electric fields, did show some significant differences from the separately housed "cage control" group (Free 1978, p. 117).

Other experiments in this series showed large cyclic variations in various plasma hormone concentrations (Free et al. 1981). Figure 3a of Free et al. (1981) shows, as a final result, serum corticosterone levels depressed in "exposed" animals. Had the experiment been terminated 6 days earlier, the opposite result would have been obtained, with "exposed" hormone levels 14 times higher than those of the "sham-exposed" controls. Explanations involving phase shift of endogenous rhythms need first to explain the amplitude of the rhythms, with a 20 -fold variation in 4 days in serum corticosterone levels of untreated acclimated animals. Examination of the data presented suggests that the weekly rotation of treatment positions (p. 107) may be relevant to the inverse relationship between "exposed" and "sham-exposed" hormone levels. Positional changes within the treatment room could have influenced both the distribution of any airborne material carried between compartments by horizontal components of the ventilation air flow and the relative efficacy of cage 
ventilation at different levels within compartments. Haine et al. (1964) associated changes in aphid moulting activity with changes in atmospheric ion polarity balance.

Using the exposure system described by Free et al. (1981), Vasquez et al. (1988) measured biogenic amines in the brains of rats exposed for 4 weeks to $39-\mathrm{kV} / \mathrm{m} 60-\mathrm{Hz}$ electric fields. Sampling at 4-h intervals throughout a single day revealed some significant interactions between time of day and type of treatment (electrically exposed/shamexposed). No details were given for animals housed outside the treatment room.

Although other interpretations are possible, these results are consistent with responses to polarity-based differences in airborne bioactive agent content between exposed and sham-exposed laboratory compartments. Air ionization was not measured in this work, or in the experiments reported by de Bruyn and de Jager (1994) who found that adult male mice, exposed to an ambient $60-\mathrm{Hz}$ electric field of $10 \mathrm{kV} / \mathrm{m}$ for $22 \mathrm{~h} /$ day in open top cages, had significantly higher corticosterone levels than control animals. Here again, body-surface corona activity cannot be excluded.

\subsection{Laboratory corona activity}

As reported in Kaune (1978a, pp. 15-18) ozone, resulting from corona ionization, was not detectable on energizing the empty rat exposure system to a field strength of $100 \mathrm{kV} / \mathrm{m}$, but was produced by a 3-cm-high-electrified metal point (radius of curvature unspecified) introduced for test purposes. Bachman et al. (1971) drew attention to the importance of specimen surface geometry and related corona discharge in electric-field experiments with plants or animals. In the US Department of Energy experiments however no details were given of laboratory air ion levels or of ozone levels from occupied animal cages. Surface electric-field measurements using a model system were reported by Kaune (1978b), and crude extrapolation from this suggests electric-field values of $6-9 \mathrm{kV} / \mathrm{m}$ at the maximum height of a resting rat in the lowest unperturbed field of $1.7 \mathrm{kV} / \mathrm{m}$ used by Wilson et al. (1981 and 1983). But Ette and Utah (1973a, b) measured corona discharge currents from grass plots in natural atmospheric electricfield strengths as low as $1.2 \mathrm{kV} / \mathrm{m}$. Recently, Goheen et al. (2004) noted that, in strong electric fields, animal hairs and whiskers could act as corona discharge sources and generate ozone. However, Pethig (1983) pointed out that high levels of ionization energy are required for ozone production. Corona air ionization may occur at field strengths below the threshold for significant production of ozone and nitrogen oxides. In the absence of data on laboratory air ion levels, possible airborne electroactivity in the US Department of Energy experiments cannot be excluded.

\subsection{Air ion studies}

If air ions were produced in these experiments, their biological activity may be important. Work at the University of California on short timescale influences on brain levels of serotonin in mice exposed, in perspex chambers, to artificial air ions (Krueger and Kotaka 1969) has been widely reported but could not be verified by Bailey and Charry (1987) using animal exposure chambers of grounded stainless steel (Charry et al. 1986). These authors used a single sampling time in all their experiments (Bailey and Charry 1987; Charry and Bailey 1985), sampling 3 h after the end of the dark period. The timing of ion exposure in Krueger's experiments is unclear however (Krueger and Kotaka 1969, p. 33), and some treatments may have ended $4 \mathrm{~h}$ after the onset of darkness. Decreases in brain serotonin in rats after 3 weeks of continuous negative ion exposure in lucite containers were reported by Diamond et al. (1980); and after 100 days of continuous negative ion treatment in wooden exposure chambers, by Gilbert (1973) who also reported reduced body weight increases. The ion exposure chambers used in this study had individual incandescent lamps providing illumination for $16 \mathrm{~h}$ daily. This long-day treatment may be relevant to the magnitude of the reported effects, with a $20 \%$ reduction in brain serotonin and $45 \%$ reduction in body weight increase. The other studies considered here used 11-12 h daylengths, with both Krueger and Kotaka (1969) and Diamond et al. (1980) using clear plastic animal housings. Only Charry and Bailey (1985) and Bailey and Charry $(1986,1987)$ were unable to detect any significant effects resulting from exposure of rats to electrically altered environments, within grounded stainless steel exposure chambers.As noted by Charry (1984, p. 352), however, air ions will be attracted to grounded components of experimental apparatus.

Charry et al. (1983) had originally developed ion exposure chambers of wood and glass construction, but no animal exposure experiments with these chambers were reported, and stainless steel exposure chambers were subsequently developed (Charry et al. 1986).

\subsection{Melatonin: EMF laboratory studies}

Wilson et al. (1981 and 1983) reported that exposure to a $60-\mathrm{Hz}$ electric field of unperturbed strength between 1.7 and $1.9 \mathrm{kV} / \mathrm{m}$ suppressed the anticipated nocturnal rise in rat pineal melatonin levels. Using the same exposure system, Reiter et al. (1988) confirmed these findings at higher field strengths $(10,65$ or $130 \mathrm{kV} / \mathrm{m})$ with no dose-response relationship. Using an exposure system of a different design, which may have reduced the possibility of crosscontamination by airborne agents however, Grota et al. 
(1994) were unable to confirm an influence on pineal melatonin. In their experiments, exposed and shamexposed animals were separated vertically, rather than horizontally as in the previous work, and would have been less influenced by any horizontal air movement.

A further study by Wilson et al. (1986) showed that "sham-exposed" nighttime pineal melatonin levels fell by nearly $50 \%$ within 3 days of cessation of electric-field treatment of experimental animals (Fig. 2 of Wilson et al. 1986). No such change should have occurred if the two environments were wholly independent. Figure 1a of the same article shows a slight increase with time in "shamexposed" pineal melatonin. Taken together, the data suggest a possible 'melatonin stimulating'agent in the "sham-exposed" environment.

Such an agent must have been something other than an electromagnetic field, and the possibility exists that melatonin inhibition also was not due to direct field action. Possible magnetic field influences on melatonin will not be considered here, but attention should again be drawn to the observation by Barnothy (1964, p. 21) that apparent biological responses to magnetic fields may actually reflect a magnetic influence on some other (perhaps airborne) agent(s).

\subsection{Simulated and actual transmission-line animal studies}

Exposure of lactating, pregnant dairy cows to the simulated environment of a $735 \mathrm{kV} 60-\mathrm{Hz}$ transmission line was reported by Burchard et al. (1996). Using 12-h photoperiods and continuous EMF exposure, animals were held indoors in wooden stalls beneath electrified metal plates, mounted $2.6 \mathrm{~m}$ above ground level, providing vertical fields of $10 \mathrm{kV} / \mathrm{m}$. Magnetic fields of $30 \mathrm{uT}$ were established by 4-m high-rectangular coils. Air ion levels were not measured and local corona activity cannot therefore be excluded. Significant increases were recorded in plasma progesterone levels and in feed intake and milk fat content. A similar experiment using non-pregnant lactating cows (Burchard et al. 2003) also recorded increased feed intake, but was accompanied by decreased milk yield and milk fat content. No significant changes in nocturnal plasma melatonin were noted in 12-h photoperiods (Burchard et al. 1998) or in 8-h daylengths (Rodriguez et al. 2004), but plasma melatonin levels were slightly lower during the light periods in these exposed animals and plasma prolactin was increased in lactating pregnant cows in short day conditions.

The influence of $60-\mathrm{Hz}$ EMF environments on melatonin in laboratory animals could not be confirmed by studies on sheep exposed to high-voltage electricity transmissionline environments (Lee et al. 1993, 1995). However, cortisol levels declined in both control and experimental animals following their movement to the proximity of the experimental site (Figs. 2, 3 and 4 in Thompson et al. 1995). During the experiment, exposed animals were held in a plastic-sided pen beneath the outer conductors of a $500-\mathrm{kV}$ transmission line and control animals were housed in a similar pen 229-m away. The high-voltage line was one of three such $500 \mathrm{kV}$ lines, together with $2 \times 230 \mathrm{kV}$ lines occupying the same transmission-line corridor. Air ionization levels were not measured, but Chalmers (1952) recorded that corona discharge ions from transmission lines could be detected at distances of $3 \mathrm{~km}$ from the source. Animals located $229 \mathrm{~m}$ from the edge of a multiple occupancy high-voltage transmission-line corridor may thus have been exposed to varying levels of EMF-associated air ionization.

Thompson et al. (1995) also reported slight, non-significant increases in experimental animal body weight and in wool fibre length. The latter observation is important as Dudgeon (1912, p. 17) noted increased wool yield and lamb production from sheep reared beneath an electrically charged wire network. No details are presently available, but many 'electro-culture' experiments at that time used direct current power sources with small-diameter overhead electrical discharge wires. Typically these were positively charged and about $0.3 \mathrm{~mm}$ in diameter to maximize surface discharge activity (see Sect. 3.7).

From field studies in the same multiple occupancy transmission line corridor as discussed by Thompson et al. (1995), there are reports of statistically significant reductions in levels of the cytokinin interleukin-1 (IL-1) in sheep penned under a 500-kV transmission line. IL-1 activity returned to control levels following removal of test animals from EMF exposure. Although cited by Hefeneider et al. (2001), the relevant reports (Stormshak 1993; Hefeneider 1994) do not appear to be publicly accessible within the UK or Ireland (British Library information).

The Hefeneider et al. (2001) article, giving details of a more recent study in which no significant differences in interleukin-1 or -2 activity were recorded, notes that due to a technical problem, electric and magnetic field strengths were reduced for part of the more recent experiments. In these, a group of animals were shielded from the powerline electric field by grounded metal screens. A statistically significant correlation was noted (p. 175) between wind direction and the difference in IL-1 activity between these shielded animals and the unshielded controls. One interpretation of the data is that electrically charged airborne agents may have depressed control sheep IL-1 levels in certain wind directions, but were prevented from influencing the shielded animals by the grounded metal screens. Air ion levels however were not measured in any of these studies. 
Exposure for 30 months to the environment of a-500 kV direct-current transmission line did not influence the productivity or health status of beef cattle held in metalmesh-sided pens immediately below the line conductors (Angell et al. 1990) when compared with control animals in similar pens $615 \mathrm{~m}$ away from the lines. Air ion levels within the pens were not directly measured but were estimated on the basis of measurements made outside the pens.

\subsection{Comment}

The aim of the preceding paragraphs has been to point out that much previous work in this field ignored the possible role of air ionization and did not determine air ion levels. These were presumably considered not relevant as the studies were designed to test for 'EMF' effects, rather than 'Electricity Utilization Environment' effects. By highlighting this point, the present article seeks to establish that alternative explanations of many of the cited experimental results cannot be excluded. Hence the need to broaden the debate.

\subsection{Plant growth studies and electro-culture}

Environmental electrical effects on plant growth have, in general, been interpreted in terms of air ionization, rather than EMF influences, as early studies related to natural atmospheric electricity and pre-dated the development of alternating-current transmission systems. Literature access difficulties however may have detracted from a current understanding of the importance of considering all components of the electricity utilization environment. Thus a recent study by Soja et al. (2003) was concerned only with electromagnetic influences on crop plant (corn and wheat) yield near a 380-kV transmission line, disregarding possible air ionization responses. In fact, using a system specifically designed to produce high levels of ionization by corona discharge from low-radius-of-curvature overhead wires, Briggs et al. (1926) obtained a $28 \%$ increase in grain yield of corn (Zea mays L.) exposed to corona activity by direct connection of the overhead discharge network to a local $6.6-\mathrm{kV}, 25-\mathrm{Hz}$ transmission line.

A study of plant growth near high-voltage powerlines (Zaidi and Khatoon 2003) was made by SCENIHR (2006) when considering possible environmental impacts of EMF. Presumably SCENIHR regarded the results as powerlineassociated, and the observations are included here as a possible corona ionization response. In this work, the authors reported HV EMF influences on pollen fertility; however, it should be noted that 7 of the $11 \mathrm{HV}$ line collection sites were near main roads and 1 from an Industrial area. Controls were more than 3-km away from any $\mathrm{HV}$ line, but detailed locations for individual specimens were not given and the results cannot therefore be ascribed with certainty to the powerline environment, rather than roadtraffic-associated atmospheric pollution.

Laboratory, glasshouse and semi-commercial studies of corona discharge air ionization influences on plant growth, including flowering, were reported by Wachter and Widmer (1976), Pohl and Todd (1981), Yamaguchi and Krueger (1983), and Yamaguchi (1985), respectively. Earlier work in electro-culture was briefly reviewed by Sidaway (1975). Valuable, but unpublished observations were recorded by the UK Electro-Culture Committee (see Appendix); these included a $118 \%$ increase in grain yield of barley (Hordeum distichon L.) after electrical treatment for one month only and various physiological responses. Reductions in cereal leaf senescence and in cereal root dry weight; increased plant height but reduced development of lateral shoots, earlier flowering and ripening, and a stronger influence on reproductive growth than on vegetative growth were all reported. The minutes of the ElectroCulture Committee meetings do not provide an obvious explanation for the decision to suspend publication of annual reports, but discussions recorded in the period 1919-1921 are relevant to this matter.

\section{Conclusions and remediation}

References cited in the previous section are important as they establish the biological activity of atmospheric ionization, presently a matter of some dispute. In all these studies the electrical environment was altered in such a way as to increase the level of air ionization in the vicinity of experimental plants, and results were interpreted in terms of air ionization, rather than EMF effects. The interaction between electro-cultural and photoperiodic responses apparent in some plant experiments suggests the possibility of a shared response pathway. Thus there are interesting similarities with electro-environmental influences on animal time-keeping mechanisms, but the role of melatonin in plants seems uncertain (Kolar and Machackova 2005).

Overall, the volume of experimental evidence justifies a call for a re-examination of Krueger's 'serotonin hypothesis' of air ion influences on biogenic amine activity in animals (Diamond et al. 1980). This research could be of particular importance at the present time, as providing an alternative mechanism for electro-environmental modulation of melatonin levels specifically, and of circadian and seasonal rhythms in general. Hofman (2004) notes that the endocrine activity of the pineal gland is influenced by neural input from the suprachiasmatic nucleus (SCN) 
which itself receives both retinal input and serotonergic input from the midbrain (Reghunandanan and Reghunandanan 2006). Changes in serotonin activity could thus impact both directly and indirectly on melatonin and other rhythms.

The Scientific Committee on Emerging and Newly Identified Health Risks (SCENIHR 2006, p. 44) notes that a 'better understanding' is required of the conflict between epidemiological data and the lack of an established mechanism to explain the increased risk of childhood leukaemia with exposure to high levels of ELF-EMF. This conclusion has been reinforced by the findings of the COMARE IIth Report (COMARE 2006) that, at least in the UK, childhood cancers other than leukaemia are also nonrandomly distributed, and the implication that similar agents may be involved in causation. There are good grounds for suggesting that present concerns about possible health hazards of ELF-EMF should be extended to consider all components of the electricity utilization environment. Even in purely economic terms, differences in remediation costs (see below) justify looking closely at alternatives to the current EMF interpretation of environmental electrical activity (see e.g., Henshaw and Reiter 2005). Certainly, a greater understanding of the possible role of air ionization impacts on areas of public health concern might prove beneficial in reducing the economic and social costs of precautionary, putative hazard remediation (von Winterfeldt et al. 2004).

Differences in overhead electricity distribution line construction for example could be relevant to some variations in demonstrability of the powerline/leukaemia link. Thus the association of childhood leukaemia with electrical wiring configurations established in Los Angeles (London et al. 1991), at variance with some other US studies, could reflect the frequent, but not universal absence of a neutral wire in this area. Although the study authors found no relation between leukaemia risk and the presence or absence of a primary distribution line neutral wire, this may be a question, which would require further investigation. Overhead distribution lines in the US normally have an "underbuilt neutral", mounted 1-1.5 m below the phase conductors (Short 2004, p. 33, 24). Experimental work may be justifiable to improve the provision of air ion grounding pathways near overhead electrical equipment, particularly in high-humidity areas.

Airborne electroactivity is environmentally sensitive, and geographical variations in the incidence of any associated adverse health impacts would be expected. Geographical epidemiological studies might thus highlight potentially beneficial aspects of the environment which could contribute to strategies to ameliorate possible hazardous agent activity. There has been much interest recently in hydrocarbon emissions from vegetation (e.g.,
Holzinger et al. 2005). These authors suggest that very reactive biogenic volatile organic compounds may have evolved as a defence mechanism to protect plant tissues by scavenging potentially hazardous atmospheric oxidants. Their work concentrated on anthropogenic, air-mass transported ozone, but theoretical consideration of the general principle might be extended to other reactive oxygen species. Negative oxygen ions have an important role in corona inception (Ruhling et al. 2003), and studies of possible powerline-associated negative health impacts in relation to atmospheric humidity and local vegetation type could prove informative. Chalmers (1952) commented on the association of corona space charge with high atmospheric humidity.

Airborne electroactivity reduction measures such as experimental forestry, horticulture, even perfume production (Ciccioli et al. 1999) should be more environmentally friendly, and less economically and socially disadvantageous than such drastic avoidance measures as powerline undergrounding and housing demolition.

Acknowledgements Although they have no responsibility for the views expressed in this article, I thank the members of the Co-ordination Group of SAGE (UK Stakeholder Advisory Group-ELF EMFs) for their encouragement to seek publication. I thank also the reviewers and editors of 'The Environmentalist' for constructive criticism and Dr. R. B. Goldberg of Information Ventures Inc. for advice on North American literature access. Most of all, I thank my wife Heather and our children Hugh and Kerry for their unfailing support, without which this work would not have been possible.

Open Access This article is distributed under the terms of the Creative Commons Attribution Noncommercial License which permits any noncommercial use, distribution, and reproduction in any medium, provided the original author(s) and source are credited.

\section{Appendix}

As previously mentioned (Sidaway 1975), the reports of the UK Electro-Culture Committee were not fully published and the only complete set of Reports available for public access within the UK appears to be that now held in The National Archives. This material was at one time held in a Ministry of Agriculture document repository and may have been subject to restriction under the 'Thirty Year Rule'. Following a request to improve access, the material was transferred to the Ministry Library in Whitehall and subsequently to the Public Record Office which has now been merged into The National Archives (of England, Wales and the United Kingdom).

\section{Address:}

The National Archives

Kew, Richmond

Surrey TW9 4DU 
$<$ http://www.nationalarchives.gov.uk>

Relevant record details are:

MAF 33/913: Ministry of Agriculture Electro-Culture Committee

First to Eighteenth and Final Report

dates: 1918-1937

MAF 33/494: Ministry of Agriculture Electro-Culture

Committee

Minutes

dates: 1918-1928 (note: this covers minutes 2-23 only).

Copies of the above material (Crown Copyright) should be available in electronic format.

\section{References}

Angell RF, Schott MR, Raleigh RJ, Bracken TD (1990) Effects of a high-voltage direct-current transmission line on beef cattle production. Bioelectromagnetics 11:273-282

Bachman CH, Hademenos DG, Underwood LS (1971) Ozone and air ions accompanying biological applications of electric fields. J Atmos Terr Phys 33:497-505

Bailey WH, Charry JM (1986) Behavioral monitoring of rats during exposure to air ions and DC electric fields. Bioelectromagnetics 7:329-339

Bailey WH, Charry JM (1987) Acute exposure of rats to air ions: effects on the regional concentration and utilization of serotonin in brain. Bioelectromagnetics 8:173-181

Barnothy JM (1964) Introduction. In: Barnothy MF (ed) Biological effects of magnetic fields. Plenum Press, New York

Briggs LJ, Campbell AB, Heald RH, Flint LH (1926) Electroculture. Bulletin 1379, US Department of Agriculture, Washington, DC

Burchard JF, Monardes H, Nguyen DH (2003) Effect of 10 kV, 30uT, $60 \mathrm{~Hz}$ electric and magnetic fields on milk production and feed intake in nonpregnant dairy cattle. Bioelectromagnetics 24:557563

Burchard JF, Nguyen DH, Block E (1998) Effects of electric and magnetic fields on nocturnal melatonin concentrations in dairy cows. J Dairy Sci 81:722-727

Burchard JF, Nguyen DH, Richard L, Block E (1996) Biological effects of electric and magnetic fields on productivity of dairy cows. J Dairy Sci 79:1549-1554

Chalmers JA (1952) Negative electric fields in mist and fog. J Atmos Terr, Phys 2:155-159

Charry JM (1984) Biological effects of small air ions: a review of findings and methods. Environm Res 34:351-389

Charry JM, Bailey WH (1985) Regional turnover of norepenephrine and dopamine in rat brain following acute exposure to air ions. Bioelectromagnetics 6:415-425

Charry JM, Bailey WH, Shapiro MH, Weiss JM (1986) Ion exposure chambers for small animals. Bioelectromagnetics 7:1-11

Charry JM, Cerniglia PA, Weiss JM, Finger RF, Michel TJ (1983) Inhalation chambers for air ion research. Bioelectromagnetics 4:167-180

Ciccioli P, Brancaleoni E, Frattoni M, Di Palo V, Valentini R, Tirone G, Seufert G, Bertin N, Hansen U, Csiky O, Lenz R, Sharma M (1999) Emission of reactive terpene compounds from orange orchards and their removal by within-canopy processes. J Geophys Res 104:8077-8094

Committee on Medical Aspects of Radiation in the Environment (COMARE) (2006) 11th Report. The distribution of childhood leukaemia and other childhood cancers in Great Britain, 19691993. Health Protection Agency, Chilton, Didcot, Oxford

de Bruyn L, de Jager L (1994) Electric field exposure and evidence of stress in mice. Environm Res 65:149-160

Diamond MC, Connor JR, Orenberg EK, Bissell M, Yost M, Krueger A (1980) Environmental influences on serotonin and cyclic nucleotides in rat cerebral cortex. Science 210:652-654

Dudgeon EC (1912) Growing crops and plants by electricity. Rentell, London

Ette AII, Utah EU (1973a) Measurement of point-discharge current density in the atmosphere. J Atmos Terr Phys 35:785-793

Ette AII, Utah EU (1973b) Studies of point-discharge characteristics in the atmosphere. J Atmos Terr Phys 35:1799-1809

Fews AP, Henshaw DL, Keitch PA, Close JJ, Wilding RJ (1999a) Increased exposure to pollutant aerosols under high voltage power lines. Int J Radiat Biol 75:1505-1521

Fews AP, Henshaw DL, Wilding RJ, Keitch PA (1999b) Corona ions from powerlines and increased exposure to pollutant aerosols. Int J Radiat Biol 75:1523-1531

Free MJ (1978) Endocrinology and male reproduction. In: Biological effects of high strength electric fields on small laboratory animals. Report HCP/T1830-03, U.S. Department of Energy, pp $115-125$

Free MJ, Kaune WT, Phillips RD, Cheng H-C (1981) Endocrinological effects of strong $60-\mathrm{Hz}$ electric fields on rats. Bioelectromagnetics 2:105-121

Gilbert GO (1973) Effects of negative air ions upon emotionality and brain serotonin levels in isolated rats. Int J Biometeor 17:267-275

Goheen SC, Gaither K, Anantatmula SM, Mong GM, Sasser LB, Lessor D (2004) Corona discharge influences ozone concentrations near rats. Bioelectromagnetics 25:107-113

Grota LJ, Reiter RJ, Keng P, Michaelson S (1994) Electric field exposure alters serum melatonin but not pineal melatonin synthesis in male rats. Bioelectromagnetics 15:427-437

Haine E, Konig HL, Schmeer H (1964) Aphid moulting under controlled electrical conditions. Int J Biometeorol 7:265-275

Hefeneider SH (1994) Joint HVAC transmission EMF environmental study: Final report on experiment 3. Bonneville Power Administration, Portland, Oregon

Hefeneider SH, McCoy SL, Hausman FA, Christensen HL, Takahashi D, Perrin N, Bracken TD, Shin KY, Hall AS (2001) Long-term effects of $60-\mathrm{Hz}$ electric vs. magnetic fields on IL-1 and IL-2 activity in sheep. Bioelectromagnetics 22:170-177

Henshaw DL, Reiter RJ (2005) Do magnetic fields cause increased risk of childood leukaemia via melatonin disruption? Bioelectromagnetics 7(Suppl):S86-S97

Henshaw DL, Ross AN, Fews AP, Preece AW (1996) Enhanced deposition of radon daughter nuclei in the vicinity of power frequency electromagnetic fields. Int J Radiat Biol 69:25-38

Hofman MA (2004) The brain's calender: neural mechanisms of seasonal timing. Biol Rev 79:61-77

Holzinger R, Lee A, Paw U KT, Goldstein AH (2005) Observations of oxidation products above a forest imply biogenic emissions of very reactive compounds. Atmos Chem Phys 5:67-75

Kaune WT (1978a) Exposure systems. In: Biological effects of high strength electric fields on small laboratory animals. Report HCP/ T1830-03, U.S. Department of Energy, pp 7-32

Kaune WT (1978b) Dosimetry. In: Biological effects of high strength electric fields on small laboratory animals. Report HCP/T1830 03, U.S. Department of Energy, pp 33-42

Kolar J, Machackova I (2005) Melatonin in higher plants: occurrence and possible functions. J Pineal Res 39:333-341

Krueger AP, Kotaka S (1969) The effects of air ions on brain levels of serotonin in mice. Int J Biometeorol 13:25-38

Lee JM, Stormshak F, Thompson JM, Thinesen P, Painter LJ, Olenchek EG, Hess DL, Forbes R, Foster DL (1993) Melatonin 
secretion and puberty in female lambs exposed to environmental electric and magnetic fields. Biol Reproduct 49:857-864

Lee JM, Stormshak F, Thompson JM, Hess DL, Foster DL (1995) Melatonin and puberty in female lambs exposed to EMF: a replicate study. Bioelectromagnetics 16:119-123

London SJ, Thomas DC, Bowman JD, Sobel E, Cheng T-C, Peters JM (1991) Exposure to residential electric and magnetic fields and risk of childhood leukemia. Am J Epidemiol 134:923-937

NRPB (2004) Particle Deposition in the Vicinity of Power Lines and Possible Effects on Health: report of an independent advisory group on non-ionising radiation and its ad hoc group on corona ions. Documents of the NRPB 15, No. 1, $55 \mathrm{pp}$

Pethig R (1983) The physical characteristics and control of air ions for biological studies. J Bioelectr 2:15-35

Pohl HA, Todd GW (1981) Electroculture for crop enhancement by air anions. Int J Biometeor 25:309-321

Reghunandanan V, Reghunandanan R (2006) Neurotransmitters of the suprachiasmatic nuclei. J Circadian Rhythms 4:2, doi: 10.1186/1740-3391-4-2

Reiter RJ, Anderson LE, Buschbom RL, Wilson BW (1988) Reduction of the nocturnal rise in pineal melatonin levels in rats exposed to $60-\mathrm{Hz}$ electric fields in utero and for 23 days after birth. Life Sci 42:2203-2206

Rodriguez M, Petitclerc D, Burchard JF, Nguyen DH, Block E (2004) Blood melatonin and prolactin concentrations in dairy cows exposed to $60 \mathrm{~Hz}$ electric and magnetic fields during $8 \mathrm{~h}$ photoperiods. Bioelectromagnetics 25:508-515

Ruhling F, Heilbronner F, Ortega P (2003) Discharge inception under impulse voltage : influence of lab air ion density and resulting charge-voltage relation. In: Smit JJ (ed) Proceedings of the 13th international symposium on high voltage engineering, Delft, Netherlands, 25-29 August 2003, paper 493

Savitz DA, Wachtel H, Barnes FA, John EM, Tvrdik JG (1988) Casecontrol study of childhood cancer and exposure to $60-\mathrm{Hz}$ magnetic fields. Am J Epidemiol 128:21-38

Scientific Committee on Emerging and Newly Identified Health Risks (SCENIHR) (2006) Preliminary opinion on possible effects of electromagnetic fields (EMF) on human health. Health and Consumer Protection Directorate General: European Commission, Brussels

Short TA (2004) Electric power distribution handbook. CRC Press, Boca Raton

Sidaway GH (1975) Some early experiments in electro-culture. J Electrostat 1:389-393
Smith SF (1978) Telephony and telegraphy, 3rd edn. University Press, Oxford

Soja G, Kunsch B, Gerzabek M, Reichenauer T, Soja A-M, Rippar G, Bolhar-Nordenkampf HR (2003) Growth and yield of winter wheat (Triticum aestivum L.) and corn (Zea mays L.) near a high voltage transmission line. Bioelectromagnetics 24:91-102

Stormshak F (1993) Joint HVAC Transmission EMF Environmental Study, Final Report on Experiment 2. Bonneville Power Administration, Portland, Oregon

Stevens RG (1987) Electric power use and breast cancer: a hypothesis. Am J Epidemiol 125:556-561

Thompson JM, Stormshak F, Lee JM, Hess DL, Painter L (1995) Cortisol secretion and growth in ewe lambs chronically exposed to electric and magnetic fields of a 60-Herz 500-kilovolt AC transmission line. J Anim Sci 73:3274-3280

Vasquez BJ, Andersen LE, Lowery CI, Adey WR (1988) Diurnal patterns in brain biogenic amines of rats exposed to $60-\mathrm{Hz}$ electric fields. Bioelectromagnetics 9:229-236

von Winterfeldt D, Eppel T, Adams J, Neutra R, DelPizzo V (2004) Managing potential health risks from electric powerlines: a decision analysis caught in controversy. Risk Anal 24:14871502

Wachter SL, Widmer RE (1976) The effects of negative air ions on plant growth. Hortscience 11:576-578

Wertheimer N, Leeper E (1979) Electrical wiring configurations and childhood cancer. Am J Epidemiol 109:273-284

Wertheimer N, Leeper E (1982) Adult cancer related to electrical wires near the home. Int J Epidemiol 11:345-355

Wilson BW, Anderson LE, Hilton DI, Phillips RD (1981 and 1983) Chronic exposure to $60-\mathrm{Hz}$ electric fields: effects on pineal function in the rat. Bioelectromagnetics 2:371-380, and 4, 293

Wilson BW, Chess EK, Anderson LE (1986) 60-Hz electric-field effects on pineal melatonin rhythms: time course for onset and recovery. Bioelectromagnetics 7:239-242

Yamaguchi FM (1985) Air ion stimulation effects on tomato plants grown in commercial soilless culture greenhouse. Soilless Cult $1: 35-53$

Yamaguchi FM, Krueger AP (1983) Electroculture of tomato plants in a commercial hydroponics greenhouse. J Biol Phys 11:5-10

Zaidi S, Khatoon S (2003) Effects of electromagnetic fields (created by high tension lines) on the indigenous floral biodiversity in the vicinity of Karachi-1: studies on PMC meiosis, meiotic products and pollen fertility. Pakistan J Bot 35:743-755 